\title{
Applying Rawlsian Approaches to Resolve Ethical Issues: Inventory and Setting of a Research Agenda
}

\begin{abstract}
Insights from social science are increasingly used in the field of applied ethics. However, recent insights have shown that the empirical branch of business ethics lacks thorough theoretical grounding. This article discusses the use of the Rawlsian methods of wide reflective equilibrium and overlapping consensus in the field of applied ethics. Instead of focussing on one single comprehensive ethical doctrine to provide adequate guidance for resolving moral dilemmas, these Rawlsian methods seek to find a balance between considered judgments and intuitions concerning particular cases on the one hand and general principles and theories on the other. In business ethics this approach is promising because it enables decision-making in a pluralist context with different stakeholders who often endorse different or even conflicting cultural and moral frameworks without giving priority to any of them. Moreover, the method is well founded in political theory. A taxonomy of different kinds of applications is developed, and classified according to the purpose, the content, and the type of justification. On the basis of this taxonomy an inventory of 12 recent applications is made. In terms of the purpose and content of the method the applications are rather diverse. Two conceptual obstacles for applying Rawlsian methods are identified, viz. inclusiveness and the communitarian objection that people have to become detached from their personal life. It is found that methodological questions, such as the question how to retrieve the relevant empirical data, are scarcely addressed in the literature. To advance the use of empirical approaches in general, and that of Rawlsian approaches in particular, it is important not only to use empirical data but to use methodological insights from social sciences in order to further advance the field of empirical ethics. It is recommended that stakeholders be given a more active role in the assessment and justification of these methods.
\end{abstract}

KEY WORDS: applied ethics, conflicting values, ethical methodology, justification, overlapping consensus, Rawls, wide reflective equilibrium
ABBREVIATIONS: WRE: Wide reflective equilibrium; OC: Overlapping consensus

\section{Introduction}

Insights from social science are increasingly used in the field of applied ethics. Questions concerning the just distribution of scarce resources (medical ethics, business ethics), risks (ethics of technology), or multiculturalism (political philosophy) are a few examples of questions applied ethicists are confronted with nowadays and which are difficult to answer on the basis of traditional ethical theories alone. Accordingly, the 1980s onwards showed a "crossing-over" between philosophy and social sciences. Philosophers in general and practical ethicists in particular, increasingly used insights from social science and vice versa. This led to a more descriptive methodology by philosophers, reconstructing, for example, the social meanings of justice in a variety of social contexts instead of adhering to strict conceptual analysis, theory construction, and critical evaluation (Birnbacher, 1999). This so-called empirical turn in applied ethics contributed to a rise in development of "context-sensitive" methodologies. In a review of empirical ethical decision-making literature in business ethics, it was found that the empirical turn did indeed contribute to knowledge on ethical decision-making but that the field lacked theoretical grounding (O'Fallon and Butterfield, 2005). Recent insights show that ethical dilemmas often require a search for individual justification within a context of conflicting moral frameworks (Coughlan, 2005; d'Astous and Legendre, forthcoming; Van de Poel and Royakkers, 2007). 
Philosophical approaches that have received ample attention in the field of applied ethics are the method of wide reflective equilibrium (WRE), initially developed by Rawls (1999 [1971]) ${ }^{1}$ and further elaborated by Daniels $(1979,1996)$, and the related method of overlapping consensus (Rawls, 1993). In the remainder of the paper I will refer to either of these as "Rawlsian approaches". Rawls developed his method as a thought process with a justificatory purpose in theory development. He wanted to develop a theory that could account for the different moral background theories people hold while maintaining that they could morally agree on certain issues. Given the diversity of moral perspectives in our pluralist society and the need to take these somehow into account, it is not surprising that the attractiveness of Rawls' method has not been limited to merely (theoretical) political philosophy. Especially in the field of applied ethics, the struggle between diverging moral frameworks is an urgent problem - for example, how to integrate the interests of multiple stakeholders (Daboub and Calton, 2002; Jamali, 2008); how to do justice to different cultural and moral traditions in international business (Ho, 2003); or how to justly distribute risks stemming from new technologies (Zandvoort, 2008)? Rawlsian approaches are attractive for answering these kinds of questions because they do not take one of the extreme positions of giving authority to either moral theory or the empirical data. Instead moral theory and empirical data are integrated in order to reach a normative conclusion with respect to moral practice (Molewijk et al., 2004). ${ }^{2}$ Moreover, whereas many empirical approaches seem to lack theoretical grounding, Rawlsian approaches are well supported by theory. In the field of business ethics the approach is promising because it allows for decisionmaking in a pluralist context with different stakeholders, without giving a priori priority to any of them. ${ }^{3}$ The latter is important to gain support for the decision made.

Although Rawlsian approaches have attracted ample attention - they are often recommended in scholarly literature as a proposed way out of an ethical impasse or as a fruitful approach to do further research on (cf. Brand-Ballard, 2003; Gracia, 1995; Van de Poel and Royakkers, 2007) - the actual application of these approaches is still relatively rare.
Consequently, insight in the actual "performance" and the potential obstacles for application is lacking.

The objective of this paper is twofold. First, by making an inventory of recent applications of Rawlsian approaches in applied ethics this paper aims at learning how the Rawlsian approaches are applied. To this end a taxonomy of different kinds of applications will be given, classified according to their purpose, content, and type of justification. Second, these applications will be studied in more detail to investigate what kind of (practical) obstacles are encountered when applying Rawlsian approaches. On the basis of the results recommendations are given, together with an identification of potential lacuna in the research.

This article proceeds as follows. First the theoretical concepts of WRE and overlapping consensus are discussed, followed by a taxonomy of different type of applications. On the basis of the outlined taxonomy different applications are discussed. To conclude, recommendations for further application of Rawlsian approaches are given.

\section{From wide reflective equilibrium to overlapping consensus}

Rawls developed the method of wide reflective equilibrium for explicating and defending his theory of justice. Rawls tried to develop a criterion of justice that would be agreed upon by all under conditions that are fair to all (JaF 15). For that he needed a point of view that is removed from and not distorted by the particular features and circumstances of the existing basic structure of society. Rawls therefore introduced the so-called "original position". Starting from this hypothetical situation, representatives of citizens are placed behind a veil of ignorance, depriving them of information about the individuating characteristics of the citizens they represent, in order to let them reflect upon and after deliberation agree upon a principle of justice that would be acceptable to all, regardless of those individuating characteristics of the citizens. This leads to the conception of justice as fairness, specifying the fair terms of social cooperation between free and equal citizens (ToJ 15; PL 22-23; JaF 18).

In addition to this "pure procedural justice" (PL 72-73), Rawls developed a justification criterion to 
assess whether the hypothetical contract situation articulates the considered convictions of political justice of individual citizens. Individuals must be able to accept the agreement reached in the original position if it can be embedded in their individual comprehensive doctrine (RH 143), i.e. if it coheres with their own firm convictions of justice or extend them in an acceptable way (ToJ 17, PL 28). People with different comprehensive doctrines must be able to justify for themselves the acceptability of the claims of political justice. Rawls introduced the idea of reflective equilibrium to refer to this individual justification. In this idea, a distinction is made between three levels of considerations:

(1) considered moral judgments about particular cases or situations;

(2) moral principles; and

(3) descriptive and normative background theories.

Assuming that all people want to arrive at a conception of justice that yields definite solutions and that is complete, in the sense that it is more than a mere collection of accidental convictions, people should aim at coherence between the considerations at the different levels. By moving back and forth between different levels of considerations and revising the considerations, principles, and theories that do not fit well, people arrive at a reflective equilibrium. We speak of an equilibrium if the different types of considerations cohere and are mutually supportive; it is called reflective if the equilibrium is arrived at by working back and forth between the different considerations and all are appropriately adjustable in the light of new situations or points of view; and it is called wide if coherence is achieved between all three levels of considerations (three-tiered view) and not only the considered judgments and moral principles (which is the case if we speak of a narrow reflective equilibrium; twotiered view). Rawls stated that "the original position serves as a mediating idea by which all are considered convictions, whatever their level of generality ... can be brought to bear on one another" (PL 26).

As already said, Rawls developed his idea of reflective equilibrium in the domain of political philosophy, as a method for deriving a theory of justice. At first, Rawls defined the reflective equilibrium in the narrow sense; a reflective equilibrium that arises through reflection on merely one's own prior convictions. However, Norman Daniels has argued that any narrow reflective equilibrium is difficult to accept, because it leaves us with the traditional two-tiered view of moral theories and is therefore particularly ill-suited to providing a basis for justification (Daniels, 1979). After all, coherence between our considered judgments and principles that provide generalization does not rule out the possibility of an arbitrarily prejudiced view point (Blackburn, 1993; Singer, 1974). The problem lies in the lack of evidence for the reliability of considered judgments independent of the principles and other theoretical elements they are supposed to support and manifest (Sencerz, 1986; Van der Burg and Van Willigenburg, 1998). By focussing solely on particular cases and moral principles, the reflective equilibrium that is arrived at is based on fixed (moral) background theories. A narrow reflective equilibrium might therefore be characterized as typically utilitarian or Kantian. Such a narrow reflective equilibrium may seem to be a descriptive rather than a justificatory method. To give the method justificatory credibility also, Daniels proposed seeking coherence between the widest set of moral and nonmoral beliefs and also including the level of background theories in the process of reflection. In order to provide evidence for the credibility of a set of moral principles and the moral conception they embody, all three levels should be scrutinized and open for revision. The result of this three-tiered criterion of justice is then wide reflective equilibrium, which also incorporates the level of background theories. In his later work, Rawls adopted this wide conception of reflection since this allows for taking into account moral conceptions advanced by others, thereby giving these the chance to influence one's own convictions (CP 289-290). Given the objective of Rawls' reflective equilibrium - the development of a concept of justice - the incorporation of moral convictions endorsed by others is part of its justification. ${ }^{4}$

The original idea of justice as fairness was based on a well-ordered society which is relative homogeneous in its basic moral beliefs and conceptions of what constitutes the good life. In his later work, Political Liberalism, Rawls revised this idea of a wellordered society. Recognizing the permanent plurality of incompatible and irreconcilable moral 
frameworks within a democratic society, he introduced the concept of overlapping consensus. People are able to live together despite conflicting moral values and ideals as long as people share a moral commitment to society's basic structure. The complete idea of justice as fairness will most probably not be part of a wide reflective equilibrium but in a plural society it can still be endorsed by adherents of reasonable comprehensive doctrines as a political conception of justice, i.e., as a basis of social unity in a constitutional democracy with a plurality of reasonable but incompatible - religious, philosophical and moral - doctrines. People with divergent comprehensive doctrines can overlap in their acceptance of a conception of justice. They do not have to agree on everything but they do agree on "principles of fairness" related to the political realm. Being the focus of an overlapping consensus, these principles specify the fair terms of cooperation among citizens and the conditions under which a society's basic institutions can be deemed just (PL 133). When all citizens recognize that they affirm the same public conception of political justice, i.e. the conception of political justice is affirmed in their own considered judgments, reflective equilibrium is not only wide but also general, by Rawls referred to as full reflective equilibrium (JaF 31). ${ }^{5}$ Because the principles are part of an overlapping consensus and not the result of a negotiation leading to some compromise, the result is more stable. With the shift from reflective equilibrium towards overlapping consensus the emphasis is also shifted away from the original position towards the distinction between public and non-public reason. ${ }^{6}$ Public reason asks us "to conduct our fundamental discussions in terms of what we regard as a political conception" (PL 241), providing as such a pro tanto justification of political values as laid down in the political conception of justice. Rawls argued that a reasonable overlapping consensus with respect to the political conception of justice (i.e. justice as fairness) is complete in the sense that "the political values specified by it ... give a reasonable answer by public reason to all, or nearly all, questions concerning constitutional essentials and basic justice" (JaF 142). This pro tanto justification of the political conception of justice is done "without looking to, or trying to fit, or even knowing what are, the existing comprehensive doctrines" (RH 145). An individual citizen can then try to fit this political conception of justice into his own comprehensive doctrine. This is what Rawls calls full justification, which is carried out by an individual citizen as a member of civil society and in which the citizen accepts a political conception and fills out its justification by embedding it in his own comprehensive doctrine. Public justification by political society, as a third kind of justification, happens "when all the reasonable members of political society carry out justification of the shared political conception by embedding it in their several reasonable comprehensive views". In the latter case, "reasonable citizens take one another into account as having reasonable comprehensive doctrines that endorse that political conception" (RH 142-143).

\section{A taxonomy of Rawlsian approaches}

Partly because of the significant revision in Rawls' theory the term "Rawlsian approaches" does allow for a rather diverse range of applications. They can vary in the purpose they serve, their content, and the kind of justification, if any, they provide. In this section I will present a taxonomy of the different type of applications. ${ }^{7}$

\section{Purpose of the method}

Rawls' method, although derived with a justificatory purpose, is sometimes used in a descriptive or even constructive way. In the latter case the method is used as a framework for structuring discussion and debate, with the aim of coming to a justified agreement. The method could then be used, for example, as a means to attain a coherent basis for decision-making by ethical committees or to gain support for particular decisions in the context of public policy (Holmgren, 1987). In the case of descriptive use, the explanatory power of the method is dependent on epistemic and cognitive considerations, for example on how people form and revise their considered judgements, moral principles, and background theories. These epistemic and cognitive considerations are less important if the model is applied with a constructive purpose. In that case the method serves a practical purpose and its effectiveness can be judged on practical grounds. 


\section{Content of the method}

Besides the threefold purpose (justificatory, descriptive, and constructive), a second important distinction lies in the content of what is to be derived by the method. With his idea of the original position Rawls developed a universal procedure for reaching moral agreement. Whatever the outcome of this procedure would be, the result is fair because it is the result of a just procedure specified by (representatives of) the citizens themselves (TJ 104, PL 72). This is called pure procedural justice: what is just is specified by the outcome of the procedure, whatever that is. As Rawls explains, "there is no prior and already given criterion against which the outcome is to be checked" (PL 73).

However, in his Theory of Justice Rawls goes further. He does not only derive procedural principles of fairness, he also gives substantive content to the principles of justice (equal basic rights and liberties, fair equality of opportunities, difference principle). ${ }^{8}$ In the application of Rawlsian approaches this distinction is often overlooked. The concepts derived from the conception of procedural justice on the one hand, and those derived from the justice principles on the other, are used almost interchangeably. However, the two are fundamentally different. Whereas the former (Rawls' concept of procedural justice), represents a (thin) procedural or political view describing under what conditions a procedure is fair, the latter (Rawls' principles of justice) represents a (thick) comprehensive view referring to the fairness of the outcome of this procedure. ${ }^{9}$ Hence, the former provides a procedure for deriving a fair or just outcome; whatever the outcome, it will be deemed just because it is derived from a fair procedure. In case of the latter, an independent criterion is given marking what outcome of the procedure can be judged fair or just (ToJ 75).

\section{Kinds of justification ${ }^{10}$}

As explained in the section "From wide reflective equilibrium to overlapping consensus", Rawls makes a distinction between three kinds of justification. The first is political justification, which is a pro tanto justification of the political conception, taking into account political values only. This is the kind of justification done in the original position by representatives of the citizens.

The second type of justification, full justification, deals explicitly with citizens within their own life and with their own comprehensive doctrine. The question here is whether they can accept the political conception and embed it in their own comprehensive doctrine. The type of equilibrium that is at stake here is individual WRE.

Public justification, as a third type, is justification by political society. Crucial here is that citizens "do not look into the content of others' doctrines, and so remain within the bounds of the political. Rather, they take into account and give some weight to only the fact - the existence - of the reasonable overlapping consensus itself' (RH 144). In this case, the shared political conception is the ground of the justification. Since all people are in WRE, there is a general reflective equilibrium also. However, each person's WRE is an individual one: the general reflective equilibrium does not coincide with the WRE. It is only insofar as the political conception of justice is concerned that the general reflective equilibrium and the individual's WRE overlap.

In the next section several applications of Rawlsian approaches will be discussed and classified according to the above-mentioned content and purpose distinctions. In case the purpose was justificatory, the type of justification will also be mentioned.

\section{Inventory of recent applications of Rawlsian approaches}

Recent applications of Rawlsian approaches to actual problems have been identified by searching the ISI Web of Knowledge databases (Web of Science, ISI Proceedings, including the Science, the Social Science, and the Arts and Humanities citation indices) and the SilverPlatter Philosopher's Index. A search on the basis of the criteria TS = ("wide reflective equilibrium" OR "overlapping consensus") and PY $=(1998-2007)$ was carried out, where TS refers to the topic search (either of these entries are found in the title, the keywords, or the abstract of an article) and PY refers to the time span within which these articles appeared. ${ }^{11}$ 
The search resulted in a list of 68 different articles, of which 12 covered an empirical or hypothetical application of the method of WRE or overlapping consensus by which I mean that Rawlsian approaches were explicitly used to elucidate a certain moral problem or justify certain solutions for a particular moral problem. In 31 articles Rawls' theory was discussed or criticized without applying it and 16 articles referred to something other than Rawls' method of WRE or overlapping consensus. ${ }^{12}$ Nine articles were left out because they were not written in English.

Table I shows the list of 12 applications including the purpose, the content, and the type of justification. A short description of each of the applications is given in the Appendix. The fifth column of the table shows whether the method of WRE or overlapping consensus (OC) was used in the paper. Of the 12 cases listed, only two applications did not cover the political domain. These were also the only applications where the method of WRE was used instead of overlapping consensus. In one case the connection was made between WRE and overlapping consensus (March 2006). ${ }^{13}$ The remaining nine articles (more or less) covered the political domain and applied the method of overlapping consensus. With respect to the dimensions "purpose" and "content", all possible combinations were covered at least once. The most prevalent combination was that of justificatory purpose and procedural content, which is similar to the way the "late" Rawls (i.e. Rawls in Political Liberalism) applied his method.

From the inventory it follows that applied ethicists are rather pragmatic in applying Rawlsian methods. In none of the papers was an attempt made to simulate something like the original position in

TABLE I

Classification of cases in terms of purpose, content, and type of justification

\begin{tabular}{|c|c|c|c|c|}
\hline Case & Purpose & Content & Type of justification ${ }^{a}$ & WRE or OC \\
\hline $\begin{array}{l}\text { Same-sex marriage } \\
\text { (McClain, 1998) }\end{array}$ & Justificatory & Procedural & Public justification & $\mathrm{OC}$ \\
\hline $\begin{array}{l}\text { The status of the EU and } \\
\text { international law } \\
\text { (La Torre, 1999) }\end{array}$ & Justificatory & Procedural & Public justification & $\mathrm{OC}$ \\
\hline $\begin{array}{l}\text { Curriculum reform } \\
\text { (Halliday, 1999) }\end{array}$ & Constructive & Substantive & - & $\mathrm{OC}$ \\
\hline $\begin{array}{l}\text { Liberal education } \\
\text { (Paris and Kimball, 2000) }\end{array}$ & Descriptive & Substantive & - & $\mathrm{OC}$ \\
\hline $\begin{array}{l}\text { European citizenship } \\
\text { (Lehning, 2001) }\end{array}$ & Constructive & Procedural & - & $\mathrm{OC}$ \\
\hline $\begin{array}{l}\text { Pediatric cochlear implants } \\
\text { (Reuzel et al., 2001) }\end{array}$ & Justificatory/constructive & Procedural & Public justification & WRE \\
\hline $\begin{array}{l}\text { International business versus } \\
\text { globalization (Ho, 2003) }\end{array}$ & Constructive/descriptive & Procedural & - & $\mathrm{OC}$ \\
\hline $\begin{array}{l}\text { Environmental values } \\
\text { (Preston, 2004) }\end{array}$ & Descriptive & Procedural & - & $\mathrm{OC}$ \\
\hline Human rights (Tobin, 2005) & Justificatory/constructive & Substantive & Public justification & $\mathrm{OC}$ \\
\hline $\begin{array}{l}\text { Muslim minorities } \\
\text { (March, 2006) }\end{array}$ & Justificatory/constructive & Substantive & Public justification & OC/WRE \\
\hline Abortion (Moran, 2006) & Justificatory & Procedural & Public justification & OC \\
\hline $\begin{array}{l}\text { Technical and technological } \\
\text { innovations in sport - seeding } \\
\text { rules in tennis } \\
\text { (Sheridan, 2007) }\end{array}$ & Justificatory/descriptive & Substantive & Political justification & WRE \\
\hline
\end{tabular}

${ }^{\mathrm{a} O n l y}$ relevant when applied with justificatory purpose. 
order to make the procedure "more fair" and increase the justificatory power. Instead the justificatory purpose was sought by taking into account the right people (viz. Ho, 2003; La Torre, 1999; Reuzel et al., 2001) or by stressing the kind of arguments that people are allowed to use (viz. McClain, 1998; Moran, 2006), or a combination of the two (March, 2006; Twiss, 2004). This is in line with the fact that most scholars refer to public justification instead of political justification. The former does, strictly speaking, not require that people are ignorant of their personal life and interests.

In seven cases the Rawlsian method had (at least) a justificatory purpose. In four cases the justificatory purpose was combined with a constructive or descriptive purpose. In two cases the purpose was purely descriptive (liberal education and environmental values) and in two cases it was purely constructive (curriculum reform and European citizenship). In none of these cases was full justification at stake. Political justification was at stake in only one case (seeding rules in tennis).

In his elaboration of WRE, Rawls makes a distinction between background theories, moral principles, and considered judgments. In the two papers that covered WRE the agreement that was sought for was a method for evaluation. Although neither of the authors explicitly mentioned on what level this agreement was to be found, in their papers they indirectly addressed the point by defining agreement as "a temporary consensus on a shared construction of the technology under scrutiny ..." (Reuzel et al., 2001, p. 252) and looking for agreement "about what they (i.e., the decision makers in tennis) consider to be the best interpretation [...] of what a fair seeding structure looks like" (Sheridan, 2007, p. 186). The similarity between Reuzel et al.'s construction and Sheridan's interpretation is striking and it suggests that the agreement cannot be framed solely in terms of one of the three levels. It is rather a certain meaning attributed to the thing being evaluated, in these cases the cochlear implant and the seeding rules. The question of how to include background theories was not discussed in detail. In the article by Reuzel et al. this issue was not dealt with at all, in the article by Sheridan the background theories were described only on a very abstract level ("a theory of the person, a theory of procedural justice, a general social theory, and a theory of the role of morality in society", p. 184). In case of overlapping consensus, the agreement was generally on the level of principles or values: liberal and democratic principles (Lehning, 2001; March, 2006; McClain, 1998; Moran, 2006), principles of Community Law (La Torre, 1999), values in education (Halliday, 1999; Paris and Kimball, 2000), values in economics (Ho, 2003), and environmental values (Preston, 2004). In the paper on human rights (Tobin, 2005), the possibility of distinguishing between the three levels was questioned. Tobin argues that when these moral principles (viz. human rights) are made substantive, "premises or assumptions that attach to the moral-social world" (viz. considered judgments) and the "comprehensive doctrines that shape these world" (viz. background theories) inevitably are built in (p. 38), thereby rejecting the Rawlsian analytical distinction. It remains to be seen to what extent this really conflicts with Rawls' own view. More important than the impossibility of distinguishing between the three levels is possibly the strong focus on moral principles. Rawls explicitly argues that his idea of wide reflective equilibrium supposes that neither background theories, nor moral principles, or considered judgments have priority over one another. Considered judgments can revise moral principles and background theories as well as vice versa. It is therefore questionable whether agreement on the level of principles is sufficient to settle moral disputes. As long as considered judgments and/or background theories significantly differ, the agreement may not be as stable as the authors suggest.

\section{Discussion}

In six out of 12 papers the application of Rawlsian approaches was judged positively (McClain, 1998; La Torre, 1999; Reuzel et al., 2001; Ho, 2003; March, 2006; Moran, 2006). According to those authors Rawlsian approaches are helpful in explicating conditions for justification (La Torre, 1999; March, 2006; McClain, 1998; Reuzel et al., 2001), and can serve as a goal of political change (Ho, 2003) or cultural transformation (Moran, 2006). Two authors took a more or less neutral stance (Lehning, 2001; Preston, 2004) and in four articles the authors took a more critical stance towards the application of 
Rawlsian approaches (Halliday, 1999; Paris and Kimball, 2000; Sheridan, 2007; Tobin, 2005). In what follows the most important points of the different articles will be briefly discussed, followed by an elaboration of the main points of criticism.

McClain (1998) discusses Rawls' overlapping consensus in the light of the question what type of arguments citizens may appeal to or what kind of reasons they may proffer to support their positions. A similar application is found in La Torre (1999). Both authors use the notion of overlapping consensus to define a criterion by which to settle disputes. McClain stresses the importance of critical examination of a supposed overlapping consensus in terms of the arguments used. La Torre emphasizes the "open ended" discursive process that should lead to the overlapping consensus. The use of Rawls' method of WRE in the article by Reuzel et al. (2001) is also similar to that of McClain. Reuzel et al. (2001) discuss the issue of feasibility and justification of interactive technology assessment (iTA) within the context of decision making on medical technologies. Reuzel et al. do not apply the method of WRE but propose it as a way to come to a justified agreement on decision making in a medical context. Similar to McClain, the authors give criteria for a reflective equilibrium. Not any agreement or equilibrium will do: a WRE is only morally justified if the considerations of all relevant actors are involved, which we can call an "inclusiveness criterion".

This question of inclusiveness is also addressed in March (2006). Where the three previous papers all described a procedural content, March uses Rawls' method to justify substantive arguments. The author argues that an Islamic doctrine of citizenship in nonMuslim liberal democracies can be said to reflect equilibrium when it is as inclusive as possible of believing Muslims without violating any essential features or aims of a well-ordered society. Besides the justification of substantive arguments, the author applies Rawls' method with a constructive purpose to stimulate discussion between different people. This constructive purpose is also found in the papers by Ho (2003) and Moran (2006). Both authors use concepts of Rawls' theory to guide political and cultural change.

Lehning (2001) and Preston (2004), who both take a more or less neutral stance towards the use of
Rawlsian approaches, use the Rawlsian notions rather loosely without explicating why and how these notions were helpful. Lehning claims that an overlapping consensus that results in a political conception of justice, shared throughout a political community, does generate a shared identity that will supersede rival identities based on, for instance, ethnicity. Preston tries to extrapolate principles of Rawls' Theory of Justice to the field of environmental ethics. Although Rawls himself does not consider environmental issues to be part of the public good and therefore not part of fundamental political justice - it is desirable that environmentalists appeal to public reason to support their claim for environmentally friendly policies, Preston argues. In his article environmental issues are the stepping stone to exploring the limits of fundamental political justice. The application of Rawlsian notions sheds some light on the topic of environmental ethics but is does not so in depth.

In the remaining four articles the authors take a more critical stance towards the application of Rawlsian approaches. Tobin (2005) rejects the claim, held by many contemporary human rights theorists, that the universality of human rights can be established by appeal to and grounded on the notion of overlapping consensus because the various belief systems on which justification of human rights are based are too divergent to provide "the kind of meaningful, substantive agreement required ... as action-guiding norms for cross-cultural moral evaluation and critique" (p. 38). Instead of grounding universality on overlapping consensus she proposes to "construct universality through actual dialogue both within and between communities" (p. 33).

The papers by Paris and Kimball (2000) and Halliday (1999) also question the feasibility of Rawls' consensus. Paris and Kimball (2000) try to give a description of the course of liberal education in the US in the twentieth century. Based on previous work by Kimball (1995a, b), in which this course was described and explained in terms of Rawls' notion of overlapping consensus, the authors revise Rawls' concept of overlapping consensus into a more pragmatic consensus which is less "thick" than Rawls' version. They thereby refer to Rawls' two principles of justice. The authors question whether these principles are as broadly supported as Rawls suggest. They therefore try to limit themselves 
to as thin a consensus as possible. This also allows for substantive changes over time if these are required. A similar course is followed by Halliday (1999). He discusses recent proposals to introduce citizenship and values education in the UK. Although widely welcomed, the values underlying this curriculum reform are open to debate. Halliday argues for a Wittgensteinian reinterpretation of overlapping consensus with regard to the political values in order to arrive at "a conception of citizenship to which all can happily assent" (p. 47). The consensus consists not so much in doctrines as on beliefs about what ought to be done in particular circumstances. The curriculum reform should not be a State affair but rather something which is done inside the locus of community.

This emphasis on community links up to the criticism raised by Sheridan (2007), who explores the use of WRE as a possible decision-making method for the rational evaluation of technical and technological innovations in sporting practices. Her paper describes the implementation of a new seeding system in male tennis at the Wimbledon championships. The WRE method is not used to justify the new seeding rules but only to hypothetically describe how the process of coming to these new rules might have developed. She argues that it is precisely in the requirement that people have to detach themselves from their own personal interests, that the method becomes too far removed from the persons' particular practices. ${ }^{14}$ Sheridan therefore rejects the method for lacking both descriptive and justificatory power.

Three main obstacles that are exemplified by the papers deserve closer attention. The first is the issue of inclusiveness (March, 2006; Reuzel et al., 2001), the second is the requirement that people have to detach themselves from their personal practices and interests (Sheridan, 2007), and the third is the issue of feasibility (Halliday, 1999; Paris and Kimball, 2000; Tobin, 2005). The remainder of this section focuses on these three issues in more detail. Discussion of the feasibility issue will show that more empirical research is needed, in particular into the question how the equilibrium or consensus is established. In the present discussions on Rawlsian approaches this issue does not seem to get the attention it deserves, as I will explain below. This section therefore concludes with recommendations for further exploration of the Rawlsian justification in practice.

\section{Inclusiveness}

The issue of inclusiveness is related to the justness of the method. In the literature on Rawls' theory it is recognized that the method has some excluding mechanism in it because it neglects the arguments of unreasonable people who refuse to accept a sufficient critical mass of common considered judgments, i.e. people who do not already have some inclination towards or belief in morality (Norman, 1998). The people Norman seems to refer to are the people on the extreme end of the reasonable-unreasonable spectrum, where the problem seems to be more of a hypothetical problem. The issue becomes more relevant as we approach the middle area of this spectrum, where it is less obvious whether or not something can count as "reasonable". This is even more true if we use it as a practical method. Methodological considerations regarding the choice about which types of beliefs and arguments to include are inevitably selective. As such the method cannot fulfill its promise of strict absence of arbitrariness (Van der Burg and Van Willigenburg, 1998). ${ }^{15}$

The criterion of inclusiveness has a second facet, which is openness. When using the method in practice the criterion of inclusiveness calls for an open discourse. In Reuzel et al. (2001), for example, it is not only important that all relevant actors are included, but that they also have equal opportunities to participate in and contribute to the decisionmaking process. If a group of researchers is engaged in a conversation with doctors and patients it is important that the vocabulary used by the experts is understandable to all. The criterion of inclusiveness also requires that people feel free to introduce unwelcome arguments. If patients are discouraged from doing so and remain silent the consensus that is arrived at cannot be deemed just.

Inclusiveness, understood this way, might conflict with the requirement that people have to deliberate in terms of public reason. After all, public reason requires people not to deliberate in terms of their comprehensive doctrines. Inclusiveness, on the contrary, requires that people are allowed to bring in 
unwelcome arguments that are important for them. The latter might be based on their private, comprehensive doctrines. In this regard it is important to distinguish between the different kinds of justification. In case of pro tanto justification the requirement of public reason is an important one, because it guarantees the "impartiality" of the justification. However, in cases of public or political justification, people's comprehensive doctrines come into play because justification is done by embedding it in the individual people's comprehensive doctrines. WRE is always about political or public justification and, consequently, when applying the method of WRE the criterion of inclusiveness "overrules" that of public reason or detachment. When applying WRE or overlapping consensus as a practical method the different kinds of justification should therefore be carefully distinguished. One should bear in mind that the type of justification determines whether priority should be given to either the criterion of public reason/detachment or to that of inclusiveness.

\section{Detachment}

The point of criticism raised by Sheridan is related to the communitarian criticism which says that the method is mistakenly aimed at people being detached from their personal life (Walzer, 1983). To justly derive principles of fairness, people are put behind a veil of ignorance, such that they are deprived of information about their position in society. However, disregarding people's context results in a "shallow" method with which people are not able to decide on important matters concerning their own life because the method becomes too far removed from the individuals' particular practices and interests, the communitarian criticism goes. People are embedded in their social environments and as such their rational morality is constituted in their community. These practices define what the moral goods are people should strive at (MacIntyre, 1984 [1981]).

In the example of the seeding rules in tennis (Sheridan, 2007), this point of criticism was especially relevant. This can be explained by the fact that the problem at stake is a very "specialized" issue within a certain community with its own particular norms and values. The disagreement amongst the different decision makers is probably not on the level of the background theories and the (moral) principles. Probably everyone agrees on the fact that the winner should preferably be the best player or the best team, hence luck should not be a decisive factor. Questions regarding how to exactly determine the winner and how to exclude luck are lower-level considerations. Hence, a narrow reflective equilibrium will probably be sufficient in those cases. However, in situations where the normative and descriptive background theories do indeed differ significantly, people will have to distance themselves from their practices, at least hypothetically. Otherwise it will be impossible to agree upon decisions. Within a certain sport practice, this will generally not be the case.

The example of the seeding rules in tennis shows that the communitarian criticism is not a knockdown argument against the application of Rawlsian approaches. Rather it shows where the application can be fruitful and where it probably cannot. Rawls developed his theory for decision making in a situation with a plurality of moral frameworks. The types of questions that are at stake in such a situation differ from those in a situation that can be characterized as relatively homogeneous. Compare, for example, a discussion in an ethics committee on the allowance of abstaining from medical treatment and a discussion within a particular sports club on the selection procedure for the best team. In the former case the interests of the patient, his relatives, and the medical doctors can significantly diverge. In the latter example a Rawlsian approach is less powerful indeed, precisely because the people of the sports club are part of the same community and to a large extent share their relevant (moral) background theories. But one could consider this also a lack of demand for Rawlsian approaches: in cases where people to a large extent share their background theories they will probably not need a systematic approach for reaching moral agreement.

\section{Feasibility}

Given the fact that all applications deal with hypothetical cases, the issue of feasibility is difficult to discuss. The authors using WRE or overlapping consensus in a constructive way emphasize that overlapping consensus is a process rather than a state 
of affairs [cf. the plea for dialogue (Tobin, 2005) and discussion (March, 2006)]. The way this process is shaped to a large extent determines the success of its outcome. Moreover, the type of questions that are addressed also determines the success of the application. Reuzel et al. (2001) argue that iTA (viz. WRE) is most suitable as a pre-assessment, generating two kinds of result:

(1) insight into the conditions under which a certain technology, or particular decisions with respect to the technology, is acceptable to all persons involved; and

(2) a set of research questions, considered relevant and feasible by all persons involved, having to be answered in order to know to what extent these conditions are, or can be, met.

This suggests that WRE and overlapping consensus, in order to be successful, requires a focus. To reach agreement about a technology in general may be too ambitious. However, if the focus is on specific changes, consequences, or implications, the approach might be more fruitful (p. 252). This focus on conditions is in line with Paris and Kimball's argument that people are more likely to agree on thin (procedural) than on and thick (substantive) notions of justice.

On the basis of hypothetical cases alone, it is premature to reject or embrace overlapping consensus or reflective equilibrium in terms of feasibility. Neither the objections raised by critics, nor the recommendations given by Reuzel et al. give a decisive answer to the question whether WRE or overlapping consensus are attainable. To answer this question, empirical research is needed.

\section{Justification in practice}

One of the striking things in the selection of articles surveyed is the lack of actor involvement in the judgment whether a reflective equilibrium or an overlapping consensus has actually been achieved. Only in the proposal by Reuzel et al. (2001) was it explicitly suggested the actors be involved in assessment of the equilibrium. In the other cases it was either left to the researcher to assess whether a reflective equilibrium or overlapping consensus had been achieved or it was left open. This can partly be explained by the fact that all cases were more or less hypothetical. However, if the method is to be used with a justificatory or constructive purpose, it will significantly gain cogency if the actual actors are directly involved in this judgment. After all, the question whether an agreement is part of an overlapping consensus or merely a matter of modus vivendi or whether someone's considered judgments, moral principles, and background theories are in reflective equilibrium can best be answered by the actor who has "direct access" to these considerations. This more empirical consideration seems to have attracted scarce attention in the literature. Musschenga indirectly addresses this point when he criticizes the feasibility of Rawlsian methods. He argues that reflective equilibrium is not an objective state of affairs that can be determined from a third-person point of view; it usually is a first-person judgment. For Musschenga this is a reason to doubt the possibility of finding a standpoint that is in equilibrium with the possibly diverse beliefs, principles, and background theories of all the members. He seems to worry more about the seeming difficulty of arriving at an equilibrium than about the question of firstperson versus third-person assessment of the equilibrium.

In real applications (as opposed to hypothetical cases) the possibility of uncovering the relevant data, i.e. the background theories, moral principles, and considered judgments deserves close attention. It is important to investigate whether these data are indeed traceable. This is an empirical question that has a high priority if one wants to explore the possibility of applying Rawlsian methods in applied ethics. Only if these data are available, it makes sense to construct or assess an equilibrium or consensus. A first step seems to be to apply the method to a real case and to ask the different actors involved about their background theories, moral principles, and considered judgments and to ask them whether they themselves conceive of the outcome as justified (within a reflective equilibrium or overlapping consensus). Of course, such a first exploration may seem slightly artificial with actors being informed about wide reflective equilibrium and the difference between overlapping consensus and modus vivendi. However, if this litmus test succeeds, it opens the door to less artificial applications. 


\section{Conclusions}

In this paper an inventory is made of 12 applications of Rawlsian approaches. Although sometimes labeled as promising within the field of applied ethics, it was found that Rawlsian approaches are still mainly applied within the political domain (i.e. they refer to the basic institutions of society). Of the 12 examples described in this paper only two did not refer to the political domain. In all applications the methods were used hypothetically. It was found that the range of applications was rather diverse in terms of purpose and content of the method.

Two conceptual (or normative) obstacles for applying Rawlsian methods were identified. The first refers to the issue of inclusiveness. For an equilibrium or consensus to be just it is important that all relevant actors are included and that they can equally engage in debate. The second obstacle is related to the communitarian objection to Rawls that people have to become detached from their personal life. The implication of the latter is that in situations where these personal concerns are important, the Rawlsian approaches loose their power. If the method is used to reach agreement between people with conflicting moral frameworks, the requirement that people are able to deliberate in terms of public reason becomes more important. Besides these normative obstacles, some authors raised doubt with regard to the feasibility of the Rawlsian approaches. It has been argued that this is an empirical question, which cannot be answered on the basis of hypothetical cases alone.

In addition to the obstacles identified it was found that in most applications the actors were not actively involved in the assessment of the equilibrium or the consensus. In order to advance the use of Rawlsian approaches in applied ethics, it would be interesting to see whether the relevant data, i.e., the considered judgments, moral principles, and background theories, can indeed be traced such as to be able to (re)construct a reflective equilibrium or consensus. Within the field of business ethics there is growing interest in the testing of ethical frameworks (cf. Giacalone et al., 2005; Robertson et al., 2008; Zarkada-Fraser, 2000), which could contribute to understanding how WRE can be established. This course should be explored further and in more depth. Methodological insights from the social sciences are essential to understanding the moral considerations and motivations of people involved. Hence, the empirical turn in applied ethics should not be limited to the use of empirical data but also to empirical methodologies.

If it turns out to be possible to assess the relevant data, the normative issues related to inclusion/ exclusion, and to a lesser extent the detachment from personal life, can be addressed. It is important that moral justification should not be left to the ethical researcher alone. All relevant actors should get an active role in the assessment of the equilibrium or consensus.

\section{Acknowledgments}

This research is part of the research program "Moral Responsibility in R\&D Networks", which is supported by the Netherlands Organization for Scientific Research (NWO) under grant number 360-20-160. I would like to thank the anonymous referees and Ibo van de Poel for reading an earlier draft of the present paper. The article has profited a lot from their comments and the helpful suggestions they provided.

\section{Appendix}

This appendix gives a brief description of the 12 applications.

Same-sex marriage (McClain, 1998)

McClain discusses Rawls' overlapping consensus in the light of the question what type of arguments citizens may appeal to or what kind of reasons they may proffer to support their positions. She illustrates this with the example of same-sex marriage and the requirements of reciprocity, i.e., the requirement to give reasons that can be understood by other citizens and that $\mathrm{s} /$ he might reasonably expect other citizens to accept (PR 797). McClain stresses the importance of critical examination of a supposed overlapping consensus and repudiation of it if it impinges on basic rights. Citizens who deliberate on political policy should support their comprehensive beliefs (i.e., arguments derived from philosophical, reli- 
gious, or moral doctrines) by reference to public reasons and political values.

The status of the EU and international law (La Torre, 1999)

In his paper La Torre presents a moral framework for the European Community law. Because Community law directly concerns and affects some of the most fundamental interests and values of Member States' citizens, Community Law is in need of a "general" and "thin" criterion by which to settle disputes between the different communities. This criterion should be based on a (minimum) common denominator of the different substantive thick legal and political communities, i.e. on an overlapping consensus between the different member states, the author argues.

\section{Curriculum reform (Halliday, 1999)}

This paper discusses recent proposals to introduce citizenship and values education in the UK. Although widely welcomed, the values underlying this curriculum reform are open to debate. Halliday argues for a Wittgensteinian reinterpretation of overlapping consensus with regard to the political values in order to arrive at "a conception of citizenship to which all can happily assent" (p. 47). The consensus consists not so much in doctrines as in beliefs about what ought to be done in particular circumstances. The curriculum reform should not be a State affair but rather something which is done inside the locus of community.

\section{Liberal education (Paris and Kimball, 2000)}

Paris and Kimball discuss the method of overlapping consensus in the context of liberal education in the US during the twentieth century. Based on previous work of Kimball, the authors compare a more pragmatic form of Rawls' overlapping consensus with the original approach as suggested by Rawls. Based on this comparison the authors argue that the emerging consensus concerning liberal education at the beginning of the 21 st century is an overlapping consensus, that is, "a consensus whose nature is pragmatic, as well as a consensus whose substantive tenets are rationalized by pragmatism" (p. 143), which is less "thick" than Rawls' version. This also allows for substantive changes over time if these are required.

European citizenship (Lehning, 2001)

Lehning discusses how questions regarding political identity and citizenship, raised by the creation of the "new Europe", can be addressed by appeal to liberal ideas of justice. The author claims that an overlapping consensus that results in a political conception of justice, shared throughout a political community, does generate a shared identity that will supersede rival identities based on, for instance, ethnicity.

Pediatric cochlear implants (Reuzel et al., 2001)

Reuzel et al. discuss the method of WRE in the light of interactive technology assessment (iTA). iTA is a kind of technology evaluation that is characterized by active stakeholder participation and deliberation. Reuzel et al. do not apply the method of WRE but propose it as a way to come to a justified agreement on decision making in medical technologies. They argue that not any agreement or reflective equilibrium will do. It is important that the reflective equilibrium is inter-subjective. Stated generally, a WRE is only morally justified if the considerations of all relevant actors are involved, with no exceptions.

International business versus globalization (Ho, 2003)

In her paper on transnational economic activities Ho uses Rawls' conception of overlapping consensus and original position to defend the shift from international business, which she conceives as a practice of mutual competition and promotion of self-interest between separate national units, to globalization. According to the latter view, the construction of a global moral community, in which there is an overlapping consensus, is encouraged. This overlapping consensus will guide economic 
institutions and business practices such that they can benefit all participants within the global community. Rawls' political conception of fairness can serve as a basis of informed and willing political agreement among free and equal participants through public reason.

\section{Environmental values (Preston, 2004)}

Preston tries to extrapolate principles of Rawls' Theory of Justice to the field of environmental ethics. Although Rawls himself does not consider environmental issues to be part of the public good and therefore not part of fundamental political justice - it is desirable that environmentalists appeal to public reason to support their claim for environmentally friendly policies. In this article environmental issues are the stepping stone to exploration of the limits of fundamental political justice.

\section{Human rights (Tobin, 2005)}

In her paper on the universality of human rights, Tobin criticizes the use of Rawls' notion of overlapping consensus to explain "how we can have meaningful agreement about human rights despite extensive cultural and moral diversity" (p. 33). By discussing the issue of equality in Islamic comprehensive doctrine, Tobin tries to show that the interpretation of equality rights in Islamic comprehensive doctrine and Western, liberal, democratic communities is fundamentally different, which renders meaningful agreement impossible. Instead Tobin proposes to construct universality through actual dialogue both within and between communities.

\section{Muslim minorities (March, 2006)}

In his article on liberal citizenship and Muslim minorities March seeks to establish "what political liberalism demands of Muslim citizens living as minorities in liberal states by way of a doctrinal affirmation of citizenship" (p. 373; italics in original). The objective of the article is to establish when it can be said that there is a consensus on the terms of social cooperation in a liberal society and thus that the comprehensive doctrine in question is providing its adherents with moral reasons for endorsing those terms.

\section{Abortion (Moran, 2006)}

The author discusses Rawls' theory in the light of the criticism expressed by former pope John Paul II that our current pluralistic, liberal society, which according to him is based on moral relativism, is in need of a transformation with regard to issues like abortion and euthanasia. Moran uses a revised version of Rawls' notion of overlapping consensus to show that one need not embrace relativism in order to defend liberalism. Although severely revised compared with Rawls' own idea of overlapping consensus, Moran's idea can be considered an application or elaboration of Rawls' original ideas. The main objective of the article is to justify procedural argumentation.

Technical and technological innovations in sport (Sheridan, 2007)

Sheridan explores the use of WRE as a possible decision-making method for rational evaluation of technical and technological innovations in sporting practices. The paper describes the implementation of a new seeding system in male tennis at the Wimbledon championships. The WRE method was not used to justify the new seeding rules but only to hypothetically describe how the process of coming to these new rules might have developed.

\section{Notes}

1 In the remainder of the text the references to Rawls' work will be denoted by the acronyms ToJ, PL, $\mathrm{JaF}, \mathrm{CP}, \mathrm{RH}$, and PR referring to $A$ Theory of Justice (Rawls, 1999 [1971]), Political Liberalism (Rawls, 1993), Justice as Fairness (Rawls, 2001), Collected Papers (Rawls, 1999), and the papers "Political Liberalism: Reply to Habermas" (Rawls, 1995) and "The Idea of Public Reason revisited" (Rawls, 1997), respectively. 
2 For a description of other approaches see Molewijk et al. (2004). For elaborate description of the main points of criticism on the use of empirical data in ethics the reader is referred to Elster (1992), Schmidt (1994), Birnbacher (1999).

3 However, as one of the reviewers correctly pointed out, ultimately a decision proposed by one of the stakeholders may be chosen as the most favourable. In that sense, one could argue that in fact priority is given to that particular stakeholder. However, this is justified only if the decision fits within each individual's WRE. The priority is then a posteriori, after the deliberative process of constructing WRE.

4 Rawls seems somewhat ambiguous at this point. On the one hand, WRE serves as an individual justification criterion. As such the inclusion of convictions held by others is part of systematizing one's own relevant convictions into "one unified, plausible conception of justice" (Pogge, 2007, pp. 166-167). Part of this coherence is to pay attention to the thoughts of others, "whose intelligence, integrity and life experience I have learned to respect" (p. 167). This aim of WRE fits well with Rawls' view on citizens as reasonable persons. On the other hand, confrontation with others forms on important motive for seeking WRE in the first place. As such, WRE is sought "not merely as a guide for conduct but also to show others that I am genuinely concerned with matters of justice and hence willing to restrain my conduct in accordance with firmly held and enduring principles" (ibid.).

5 Note that this is not to say that this general reflective equilibrium is shared by all. It is only with regard to the political conception of justice as fairness that the general reflective equilibrium is a shared wide reflective equilibrium.

6 Rawls provides a threefold meaning for public reason: "it is the reason of the public; its subject is the good of the public and matters of fundamental justice; and its nature and content is public, being given by the ideals and principles expressed by society's conception of political justice" (PL 213). He explicitly rejects the distinction public-private in the context of political liberalism, because there is no such thing as private reason involved. Besides public reason there is social reason, concerned with associations in society, and there is domestic reason, concerned with families as small groups in society. Citizens participate in all these kinds of reason (PL 220; fn 7).

7 A word of caution is due here. With the introduction of Rawlsian approaches to the field of applied ethics, we extend the application domain beyond the political. Moreover, for Rawls the concepts were used mainly hypothetically with the purpose of developing a theory of justice. In applied ethics actual decision problems are at stake, which calls for other than merely hypothetical considerations. This necessarily implies that different versions of the original method are being used, depending on the issue at stake. A certain pragmatic stance is therefore required in using Rawlsian approaches (Van der Burg and Van Willigenburg, 1998).

8 Note that this is exactly the point where Rawls has attracted most criticism. Opponents argue that it is intrinsically impossible to fairly derive procedurally neutral principles for the political domain and at the same time endorsing a comprehensive view of how those principles are to be substantiated. There seems to be an unbridgeable gab between a political doctrine of liberalism (i.e. to be tolerant towards non-liberal comprehensive doctrines) and endorsing political liberalism as a comprehensive doctrine at the same time (cf. Tan, 1998).

9 The thin-thick distinction is often made with regard to liberalism. A thin conception of liberalism is primarily aimed at tolerance towards other comprehensive doctrines. No single comprehensive doctrine can have the ultimate authority in political debate. Thick liberalism is itself a comprehensive doctrine with a particular view on the good life in which the values of autonomy and individuality extend into most areas of life.

10 For the sake of analytical clarity the way the three kinds of justification are approached is slightly different from Rawls' approach.

11 Other sources for papers on WRE/overlapping consensus applications are available but the objective of this research is not give a complete inventory of all applications of WRE/overlapping consensus. Rather, the objective is to obtain a random sample of applications of Rawlsian approaches.

12 The term "overlapping consensus" seemed to be a microbiological term as well, referring to a particular genetic phenomenon.

13 March did in fact not refer to wide reflective equilibrium but to reflective equilibrium, leaving the question whether this is a wide or narrow equilibrium open. 14 Although practice is not part of Rawls' own vocabulary, it is a notion often used by communitarians to refer to the MacIntyrian idea of socially-established cooperative human activity. Because these practices are constitutive for the good life, it would be wrong to demand that people detach themselves from a practice and the motives, considerations, and interests that follow from being part of it. The full definition of MacIntyrian practice reads as follows: a practice is "any coherent and complex form of socially established co-operative human activity through which goods internal to that form 
of activity are realized in the course of trying to achieve those standards of excellence which are appropriate to, and partially definitive of, that form of activity, with the result that human powers to achieve excellence, and human conceptions of the ends and goods involved, are systematically extended" (MacIntyre, 1984 [1981], p. 187).

15 Van der Burg and Van Willigenburg use the word bias instead of arbitrariness. I prefer the latter since bias indicates a systematic selectivity, which does not necessarily have to be the case. The point is that every selection implies a line to be drawn between what to include and what not. The drawing of such a line is intrinsically selective. This selectivity may, but does not necessarily have to be, biassed also.

\section{References}

Birnbacher, D.: 1999, 'Ethics and Social Science: Which Kind of Co-operation?', Ethical Theory and Moral Practice 2(4), 319-336.

Blackburn, S.: 1993, 'Can Philosophy Exist?', in J. Couture and K. Nielsen (eds.), Méta-Philosophie: Reconstructing Philosophy? New Essays on Metaphilosophy (University of Calgary Press, Calgary), pp. 163-187.

Brand-Ballard, J.: 2003, 'Consistency, Common Morality, and Reflective Equilibrium', Kennedy Institute of Ethics Journal 13(3), 231-258.

Coughlan, R.: 2005, 'Codes, Values and Justifications in the Ethical Decision-Making Process', Journal of Business Ethics 59(1-2), 45-53.

d'Astous, A. and A. Legendre: Forthcoming, 'Understanding Consumers' Ethical Justifications: A Scale for Appraising Consumers' Reasons for Not Behaving Ethically', Journal of Business Ethics.

Daboub, A. J. and J. M. Calton: 2002, 'Stakeholder Learning Dialogues: How to Preserve Ethical Responsibility in Networks', Journal of Business Ethics 41(1-2), 85-98.

Daniels, N.: 1979, 'Wide Reflective Equilibrium and Theory Acceptance in Ethics', Journal of Philosophy 76, 256-282.

Daniels, N.: 1996, Justice and Justification. Reflective Equilibrium in Theory and Practice (Cambridge University Press, Cambridge).

Elster, J.: 1992, Local Justice. How Institutions Allocate Resources and Necessary Burdens (Cambridge University Press, New York).

Giacalone, R. A., K. Paul and C. L. Jurkiewicz: 2005, 'A Preliminary Investigation into the Role of Positive Psychology in Consumer Sensitivity to Corporate
Social Performance', Journal of Business Ethics 58(4), 295-305.

Gracia, D.: 1995, 'Hard Times, Hard Choices - Founding Bioethics Today', Bioethics 9(3-4), 192-206.

Halliday, J.: 1999, 'Political Liberalism and Citizenship Education: Towards Curriculum Reform', British Journal of Educational Studies 47(1), 43-55.

Ho, A.: 2003, 'International Business vs. Globalization: Implications for Business Ethics', Business and Professional Ethics Journal 22(2), 51-69.

Holmgren, M.: 1987, 'Wide Reflective Equilibrium and Objective Moral Truth', Metaphilosophy 18(2), 108-124.

Jamali, D.: 2008, 'A Stakeholder Approach to Corporate Social Responsibility: A Fresh Perspective into Theory and Practice', Journal of Business Ethics 82(1), 213-231.

Kimball, B. A.: 1995a, 'Introduction', in R. Orrill (ed.), The Condition of Liberal Education (College Entrance Examination Board, New York), pp. xxii-xxiii.

Kimball, B. A.: 1995b, 'Toward Pragmatic Liberal Education', in R. Orrill (ed.), The Condition of Liberal Education (College Entrance Examination Board, New York), pp. 3-127.

La Torre, M.: 1999, 'Legal Pluralism as Evolutionary Achievement of Community Law', Ratio Juris: An International Journal of Jurisprudence and Philosophy of Law 12(2), 182-195.

Lehning, P. B.: 2001, 'European Citizenship: Towards a European Identity?', Law and Philosophy 20(3), 239-282.

MacIntyre, A.: 1984[1981], After Virtue: A Study in Moral Theory (University of Notre Dame Press, Notre Dame).

March, A. F.: 2006, 'Liberal Citizenship and the Search for an Overlapping Consensus: The Case of Muslim Minorities', Philosophy \& Public Affairs 34(4), 373-421.

McClain, L. C.: 1998, 'Deliberative Democracy, Overlapping Consensus, and Same-Sex Marriage', Fordham Law Review 66(4), 1241-1252.

Molewijk, B., A. M. Stiggelbout, W. Otten, H. M. Dupuis and J. Kievit: 2004, 'Empirical Data and Moral Theory. A Plea for Integrated Empirical Ethics', Medicine, Health Care and Philosophy 7, 55-69.

Moran, J.: 2006, 'Religious Reasons and Political Argumentation', Journal of Religious Ethics 34(3), 421437.

Norman, W.: 1998, “Inevitable and Unacceptable": Methodological Rawlsianism in Anglo-American Political Philosophy', Political Studies 46(2), 276-294.

O'Fallon, M. J. and K. D. Butterfield: 2005, 'A Review of the Empirical Ethical Decision-Making Literature: 1996-2003', Journal of Business Ethics 59(4), 375-413.

Paris, D. C. and B. A. Kimball: 2000, 'Liberal Education: An Overlapping Pragmatic Consensus', Journal of Curriculum Studies 32(2), 143-158. 
Pogge, Th. W.: 2007, John Rawls: His Life and Theory of Justice (Oxford University Press, Oxford).

Preston, T.: 2004, 'Environmental Values, Pluralism, and Stability', Ethics, Place and Environment 7(1-2), 73-83.

Rawls, J.: 1993, Political Liberalism (Columbia University Press, New York).

Rawls, J.: 1995, 'Political Liberalism: Reply to Habermas', The Journal of Philosophy 92(3), 132-180.

Rawls, J.: 1997, The Idea of Public Reason Revisited (University of Chicago Law Review, Chicago), p. 64.

Rawls, J.: 1999[1971], A Theory of Justice (Revised Edition ed.) (The Belknap Press of Harvard University Press, Cambridge).

Rawls, J.: 1999, Collected Papers (Revised Edition ed.) (Harvard University Press, Cambridge).

Rawls, J.: 2001, Justice as Fairness. A Restatement (The Belknap Press of Harvard University Press, Cambridge, MA).

Reuzel, R. P. B., G. J. Van der Wilt, H. A. M. J. Ten Have and P. E. D. Robbe: 2001, 'Interactive Technology Assessment and Wide Reflective Equilibrium', Journal of Medicine and Philosophy 26(3), 245-261.

Robertson, C. J., B. J. Olson, K. M. Gilley and Y. Bao: 2008, 'A Cross-Cultural Comparison of Ethical Orientations and Willingness to Sacrifice Ethical Standards: China Versus Peru', Journal of Business Ethics 81(2), 413-425.

Schmidt, V. H.: 1994, 'Bounded Justice', Social Science Information 33, 305-333.

Sencerz, S.: 1986, 'Moral Institutions and Justification in Ethics', Philosophical Studies 50, 77-95.

Sheridan, H.: 2007, 'Evaluating Technical and Technological Innovations in Sport - Why Fair Play isn't Enough', Journal of Sport \& Social Issues 31(2), 179-194.
Singer, P.: 1974, 'Sidgwick and Reflective Equilibrium', The Monist 58, 490-517.

Tan, K. C.: 1998, 'Liberal Toleration in Rawls's Law of Peoples', Ethics 108(2), 276-295.

Tobin, T.-W.: 2005, 'The Non-Modularity of Moral Knowledge: Implications for the Universality of $\mathrm{Hu}-$ man Rights', in J. R. Rowan (ed.), Social Philosophy Today: Human Rights Religion and Democracy (Philosophy Documentation Center, Charlottesville), pp. 3350.

Twiss, S. B.: 2004, 'History, human rights, and globalization', Journal of Religious Ethics 32(1), 39-70.

Van de Poel, I. and L. Royakkers: 2007, 'The Ethical Cycle', Journal of Business Ethics 71(1), 1-13.

Van der Burg, W. and T. Van Willigenburg: 1998, 'Introduction', in W. Van der Burg and T. Van Willigenburg (eds.), Reflective Equilibrium. Essays in the Honour of Robert Heeger (Kluwer Academic Publishers, Dordrecht/Boston/London), pp. 1-25.

Walzer, M.: 1983, Spheres of Justice: A Defense of Pluralism and Equality (Basic Books Inc., New York).

Zandvoort, H.: 2008, 'Risk Zoning and Risk Decision Making', International Journal of Risk Assessment and Management 8(1-2), 3-18.

Zarkada-Fraser, A.: 2000, 'A Classification of Factors Influencing Participating in Collusive Tendering Agreements', Journal of Business Ethics 23(3), 269-282.

Department of Technology, Policy, and Management, Delft University of Technology, P.O. Box 5015, 2600GA, Delft, The Netherlands E-mail: N.Doorn@tudelft.nl 